\title{
Creating Medical Terminology Flashcards for Use in Specialized Language Courses at Medical Sciences Universities
}

\section{Iman Alizadeh $^{1 *}$, Yasaman Ramazanzad ${ }^{2}, \&$ Safoura Sharifi $^{2}$}

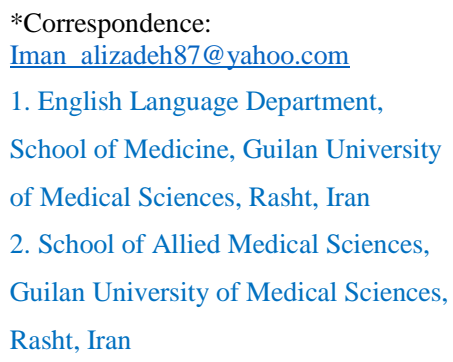

*Correspondence:

Iman_alizadeh87@yahoo.com

1. English Language Department,

School of Medicine, Guilan University

of Medical Sciences, Rasht, Iran

2. School of Allied Medical Sciences,

Guilan University of Medical Sciences,

Rasht, Iran

Received: 13 April 2021

Revision: 14 June 2021

Accepted: 17 July 2021

Published online: 20 September 2021

\begin{abstract}
This study aimed to create medical terminology flashcards in the form of teaching and learning aids for use in the specialized language and medical terminology courses at Guilan University of Medical Sciences, Iran. To achieve the objective of the study, first, a needs analysis was conducted, which showed the scarcity of such educational materials and students' needs for them. Next, the structure and the content of information of the flashcards were developed; then, the designed flashcards were examined and modified. Afterwards, professors who were experienced in teaching medical terminology and specialized language courses evaluated the flashcards using a questionnaire. Moreover, an interview was conducted with the professors on ways to improve the quality of the flashcards. The results showed that the professors were satisfied with the potential learning effects, the structure, and the content of information of the flashcards. They also suggested a few modifications to the flashcards and recommended that the flashcards should be used in the university courses. The study has implications for the development of educational materials in the form of teaching and learning aids.
\end{abstract}

Keywords: flashcards, medical terminology, educational materials, professors 


\section{Introduction}

Academic writing is a productive activity that demands critical reading of educational materials and reconstructing Medical terminology constitutes an essential part of education in health professions; proficiency in medical terms can guarantee successful communication in the clinical fields and the communication between health professionals and patients (Seidlein et al., 2020). Because of the importance of medical terminology in the academic and professional life of the students of medical sciences, it is included in the curriculum of medical disciplines in the form of an independent course or as part of the specialized language course. Traditionally, most Iranian educational institutions tend to use textbooks and take up wordlists as a technique for teaching words (Mohammadnejad, Nikdel, \& Oroujlou, 2012) through PowerPoint and overhead projectors. Research has shown that though effective in some situations, using PowerPoint to teach terms has proved unsuccessful as it does not engage students (Hagood, 2012). Therefore, it is necessary to produce appropriate educational materials in the form of teaching and learning aids to facilitate and improve students' learning of Latin and Greek medical terms.

\subsection{Statement of the Problem and Significance of the Study}

In a typical medical terminology course, the professor, who is in charge of the course, usually introduces the resources, pronounces medical terms, prefixes and suffixes, gives the Persian equivalent of the terms, prefixes and suffixes, and asks students to do relevant homework and exercises in the introduced resources. The resources which are mainly medical terminology dictionaries are in the English language and employ a stepwise approach to teaching medical terminology by describing how medical terms are built from word parts, introducing body structures, diseases, and treatments, and describing each body system. Educational technology in the form of teaching and learning aids can contribute to the learning and teaching of medical terms. Tomlinson (1998) describes teaching aids including textbooks, homework books, and flashcards as tools used for learning and teaching. The integration of multimedia into English learning and teaching has also become a trend (Hu \& Deng, 2007). Therefore, teaching aids such as flashcards can be used to facilitate the learning process of medical terms.

A search for educational materials in the Iranian context, however, showed that medical terminology flashcards are neither available nor readily downloadable. Khabiri and Khatibi (2013) note that one of the reasons why Iranian students do not use educational technologies is that many educational technologies are not downloadable in Iran because of sanctions against the country; they further add that the available technologies are so expensive that most learners cannot afford them. Bryson (2012) points out that medical terminology flashcards can be bought or downloaded as ready-made sets like Mosby's Flashcards for medical terminology. Bryson (2012) notes that in contexts where the flashcards are not available, teachers and students can make the flashcards themselves, describing the teacher or student-made flashcards as the "best" since the production phase of the flashcards "becomes part of the learning process." He further adds that developing flashcards can be beneficial especially for difficult subjects like anatomy, physiology, or any subject where there are many new words and terms. Therefore, the development of flashcards in the form of teaching and learning materials can be of great help in a situation where there is a scarcity of teaching and learning resources and materials.

It should also be noted that teaching materials can be different in terms of attractiveness, preferences, and the effect on learning (Akhoundzadeh, Salehi, \& Yousefi, 2010); therefore, they need to be evaluated before being used in university courses. Tomlinson (2003) introduces the evaluation of educational materials as a process of examining learning materials to establish their value. Assessment of educational materials can be done before, during, and after using them. Rubdy (2003) reports that the pre-use evaluation of educational materials helps teachers and learners know what uses they can make of them. According to McDonough and Shaw (2003), evaluation during and after the use of educational materials helps understand how successful these tools are in teaching. Given the existing needs for educational resources for medical terminology courses, the present study was set out with the aim of designing and developing medical terminology flashcards to be used in Iranian medical sciences universities. The present study also intended to evaluate the developed medical terminology flashcards from the perspective of professors before using them in university classes.

\subsection{Research Questions}

To address the objectives of the study, the following research questions were formulated.

1. How positive is the faculty members' evaluation of different aspects of the medical terminology flashcards? 
2. What suggestions do the faculty members make to improve the quality of the medical terminology flashcards?

\section{Review of the Literature}

According to Nation (2001), knowledge of vocabulary constitutes an essential part of learners' general language proficiency and is required for successful communication. Studies in the area of vocabulary learning techniques (Khorasani \& Mirhosseini Chahardeh, 2018; Mahdiloo \& Izadpanah, 2017; Pakdaman \& Pourhosein Gilakjani, 2019; Shamsi \& Rahimy, 2017) and the benefits of flashcards in learning vocabulary abound (Farrokhi, Zohrabi, \& Bolandnazar, 2021; Lisa, 2019; Sitompul, 2013; Taghizadeh \& Porkar, 2018).

Farrokhi, Zohrabi, and Bolandnazar (2021), for example, investigated the effect of flashcards and wordlist strategies on Iranian intermediate EFL learners' concrete and abstract vocabulary learning. The results of the study indicated that, on the immediate posttest and the delayed posttest, there was not a difference between the learners' average scores when learning words with flashcards and wordlists. They, however, noted that the hypothesis that flashcards could result in better learning than wordlists was only partially supported by the study, adding "It might be inferred that the words memorized using flashcards remain for a longer period of time in the learners' memory than words memorized using wordlists." The study also showed that there was a statistically significant difference between the learning of concrete and abstract words among the Iranian intermediate EFL learners, noting that the "concrete words are more likely to be recalled by students compared to abstract words."

İn a similar study in the Iranian context, Taghizadeh and Porkar (2018) examined the effect of using flashcards, SMS, and tablet on EFL learners' vocabulary knowledge and attitudes. To do so, they recruited forty-five Iranian advanced EFL learners and divided them into three groups. The first group used tablets to learn the vocabulary items, the second group learned vocabulary via SMS, and the third group used flashcards. The results of the study showed that the three methods of teaching vocabulary (SMS, flashcard, and tablet) positively influenced the learners' performance on the vocabulary test. Most of the learners who had employed flashcards reported that the flashcard method significantly contributed to their English vocabulary learning, adding that the flashcard method could help flexible English vocabulary learning anywhere and at any time.

Baleghizadeh and Ashoori (2011) also compared the influence of flashcards and wordlists as two English vocabulary teaching techniques on learners' vocabulary learning. To do so, they purposefully sampled the learners from a junior high school and divided them into the flashcard group and wordlist group. The learners took immediate and delayed posttests. The results of the statistical analysis showed that the flashcard group (16.83) had a slightly higher average score than the wordlist group (15.55). The study concluded that, despite the outperformance of the learners in the flashcard group, neither of the two techniques were efficient enough in teaching vocabulary.

Likewise, Sitompul (2013) compared the effect of using flashcards and wordlist on students' English vocabulary learning. The results of the study showed that both strategies improved the students' vocabulary learning. The students using flashcards also reported that "they could memorize the words easily, be more motivated to learn English and understand vocabulary easily." Lisa (2019) also investigated the impact of illustrated flashcards on the motivation to learn English vocabulary among elementary school students. The study showed that there was a significant difference between the motivation to learn English vocabulary among the students before and after using the flashcards. The study concludes that flashcards yield a better result when they are used as follow-up exercises in teaching vocabulary.

Yüksel, Mercanoğlu, and Yılmaz (2020) also examined the impact of digital flashcards and wordlists on students' learning of technical vocabulary. They also investigated the students' perceptions of the use of digital flashcards. To achieve the objectives of the study, they used the convenient sampling method and recruited a total of 57 undergraduate pharmacy students. They collected data using a pre-treatment survey, two technical vocabulary tests, and a posttreatment survey. The findings of the study demonstrated that the students using digital flashcards outperformed in learning technical vocabulary and had positive perceptions about the use of digital flashcards to study technical vocabulary. They concluded that teacher-prepared digital flashcards could lead to better technical vocabulary learning.

\section{Methodology}

\subsection{Design of the Study}

This study is a Scholarship of Teaching and Learning (SoTL) research work. The SoLT is defined as "viewing the world of the classroom as a site for inquiry, asking, and answering questions about students' learning in ways that can improve one's own classroom and also advance the larger profession of teaching" (Huber \& Hutchings, 2005, p. 1). 
It employed a mixed-methods research design to address the objectives of the study. As a result, it used a questionnaire and semi-structured interviews to collect data.

\subsection{Participants}

The participants in the present study were the reviewers of the flashcards (7), and the professors who evaluated the flashcards (14). The reviewers of the flashcards were two English language teaching professors, a nursing professor, a biochemistry professor, a microbiology professor, a physiology professor, and an anatomy professor. The professors held a Ph.D. in their relevant fields and had at least a three year-experience of teaching at university. The participants who evaluated the flashcards were male (9) and female (5) professors with at least five years of experience in teaching medical terms. They specialized in teaching English (6), nursing (3), midwifery (2), microbiology (1), bacteriology (1), and biochemistry (1).

\subsection{Instrument}

A questionnaire with items on different aspects of the flashcards was used in the study. The questionnaire was developed based on the steps recommended by Dörnyei (2010). The questionnaire was piloted and, as a result, some items were modified. A Cronbach Alpha test was used to compute the reliability of the questionnaire, which was calculated at 0.81 . The content validity of the questionnaire was confirmed by experts in the field of English language teaching. Additionally, to ensure the usability of the flashcards, an interview was performed with the professors. During the interview, they were asked whether the flashcards could be used in the university courses; they were also asked to give their suggestions to improve the flashcards.

\subsection{Data Collection}

The idea of producing the flashcards germinated in the mind of the researchers in the second semester of the 2018 academic year after discovering the lack of medical terminology flashcards and the need for them. To design the flashcards, the researchers identified some flashcard-making software like Anki, Brainspace and Quizlet, Cram, and IDoRecall. However, because of some limitations, the researchers decided to use Microsoft 7's Word, PowerPoint, and Acrobat. The designing phase of the flashcards is briefly explained below.

-The medical terminology dictionary entitled Medical terminology: An illustrated guide by Cohen and DePetris (2018) was chosen as the reference book.

-It was decided that the flashcards be designed and developed based on the medical terms of each of the body systems.

-For each body system, a flashcard was designed as the "Guide." On this flashcard, the colors of each part of the medical terms and abbreviations used on the flashcards were indicated.

-For each body system, an independent color was used to help students differentiate each flashcard from others. For aesthetic purposes, different types of information contained on a flashcard were shown with specific colors on the front and back of the flashcards.

-The front side of each flashcard contained information on the body system, the medical term, and an example sentence in which the medical term was used.

-The backside of the flashcards contained information on the Persian equivalent of the medical terms, and the components of the terms (root, prefix, suffix) together with their meaning in English.

An image was used to help students' understanding of the meaning of the terms where it was possible. After finalizing the designing phase of the flashcards, they were given to a group of reviewers, who were asked to examine the flashcards in terms of the content of information, wording, readability, the organization of the information on the front and back, and the aesthetic features. They were asked to scrutinize the flashcards, comment on different parts of the flashcards, and make suggestions for the improvement of the flashcards. The reviews were collected and a panel session was organized in which the reviewers discussed the ways to improve the quality of the flashcards. Based on the reviewers' corrections, comments, and suggestions, and the results of the panel session, the flashcards were modified and finalized. 
The flashcards were then given to the professors who were asked to evaluate them. To this end, the researcherdeveloped questionnaire was used. There were as many as 500 flashcards that covered the key medical terms on the cardiovascular system (180 roots, prefixes, and suffixes), nervous system (100 roots, prefixes, and suffixes), respiratory system (170 roots, prefixes, and suffixes), and blood and immunity system (100 roots, prefixes, and suffixes). Each flashcard contained a target word together with information on the root, prefix, and suffix, and the Persian equivalent of the word. Moreover, an English sentence containing the target word was given. The rationale for selecting the medical vocabularies was the inclusion of the vocabularies in the medical dictionary which has been prescribed by the Iranian Ministry of Health, Health and Treatment for teaching medical terminology courses at medical sciences universities.

\subsection{Data Analysis}

To analyze the data, first, the questionnaires which were distributed among the faculty members were collected. Then, the data were fed into the SPSS 22.0 version. Descriptive statistics such as mean, frequency, and percentage were used to analyze the quantitative data. To analyze the qualitative data, which were collected in the interviews conducted with the professors, conventional content analysis was used.

\section{Results}

One of the objectives of the study was to determine the professors' evaluation of the three aspects of the flashcards: The appearance and structure of the flashcards, the content of information of the flashcards, and the potential effect of the flashcards on learning medical terms. Table 1 below shows the mean score of the professors' evaluation of the flashcards in terms of the three aspects.

Table 1. The professors' evaluation of the three aspects of the flashcards

\begin{tabular}{lllll}
\hline Aspects & $\mathrm{N}$ & Mean & Minimum & Maximum \\
\hline Potential effect on learning & 14 & 40.8571 & 24.00 & 50.00 \\
Content of information & 14 & 31.8571 & 25.00 & 35.00 \\
Appearance and structure & 14 & 31.3571 & 25.00 & 35.00 \\
\hline
\end{tabular}

As the table shows, the mean score (40.8571) of the professors' evaluation of the potential effect of the flashcards on learning was the highest, which was followed by the mean score (31.8571) of their evaluation of the content of information of the flashcards and the mean score (31.3571) of their evaluation of the appearance and structure of the information on the flashcards. The analysis of the professors' evaluation of the structure and appearance of the flashcards is given in Table 2 below.

Table 2. The professors' evaluation of the structure and appearance of the flashcards

\begin{tabular}{llllllll}
\hline & Item 1 & Item 2 & Item 3 & Item 4 & Item 5 & Item 6 & Item 7 \\
\hline $\mathrm{N}$ & 14 & 14 & 14 & 14 & 14 & 14 & 14 \\
Mean & 4.4286 & 4.2857 & 4.7143 & 4.7143 & 4.2143 & 4.5000 & 4.5000 \\
$\mathrm{SD}$ & .85163 & 1.06904 & .46881 & .46881 & .80178 & .51887 & .51887 \\
Min & 2.00 & 2.00 & 4.00 & 4.00 & 2.00 & 4.00 & 4.00 \\
Max & 5.00 & 5.00 & 5.00 & 5.00 & 5.00 & 5.00 & 5.00
\end{tabular}

As the table shows, the mean score of the professors' evaluations of all items on the appearance of the flashcards was high. Among the items, items number three (4.7143) and four (4.7143) had the highest mean score. Item number five (4.2143) had the lowest mean score. Table 3 below shows the analysis of the professors' evaluation of the content of information on the flashcards. 
Table 3. The professors' evaluation of the content of the flashcards

\begin{tabular}{llllllll}
\hline & Item 1 & Item 2 & Item 3 & Item 4 & Item 5 & Item 6 & Item 7 \\
\hline $\mathrm{N}$ & 14 & 14 & 14 & 14 & 14 & 14 & 14 \\
Mean & 4.5000 & 4.6429 & 4.2143 & 4.4286 & 4.7143 & 4.6429 & 4.7143 \\
$\mathrm{SD}$ & .65044 & .49725 & .89258 & .64621 & .46881 & .49725 & .46881 \\
Min & 3.00 & 4.00 & 2.00 & 3.00 & 4.00 & 4.00 & 4.00 \\
Max & 5.00 & 5.00 & 5.00 & 5.00 & 5.00 & 5.00 & 5.00 \\
\hline
\end{tabular}

The table shows that the professors had a positive evaluation of the content of the flashcards. Items five (4.7143) and seven (4.7143) received the highest score. The professors, however, gave the lowest score to item three (4.2143). The results of the professors' evaluation of the effect of the flashcards on learning are given in Table 4 below.

Table 4. The professors' evaluation of the learning effect of the flashcards

\begin{tabular}{lllllllllll}
\hline & Item 1 & Item 2 & Item 3 & Item 4 & Item 5 & Item 6 & Item 7 & Item 8 & Item 9 & Item10 \\
\hline $\mathrm{N}$ & 14 & 14 & 14 & 14 & 14 & 14 & 14 & 14 & 14 & 14 \\
Mean & 4.1429 & 4.1429 & 3.9286 & 3.7857 & 4.0000 & 4.3571 & 4.2143 & 4.0714 & 4.0714 & 4.1429 \\
$\mathrm{SD}$ & .86444 & .86444 & .73005 & .80178 & .87706 & .74495 & .69929 & .61573 & .73005 & .86444 \\
Min & 2.00 & 2.00 & 2.00 & 2.00 & 2.00 & 3.00 & 3.00 & 3.00 & 3.00 & 2.00 \\
Max & 5.00 & 5.00 & 5.00 & 5.00 & 5.00 & 5.00 & 5.00 & 5.00 & 5.00 & 5.00 \\
\hline
\end{tabular}

From the table, it can be understood that the professors believed that the flashcards would positively affect learning. Item six had the highest mean score (4.3571), and item three had the lowest mean score (3.9286). The analysis of the professors' answers in the interviews showed that their suggestions centered around the inclusion of the pronunciation of the terms, modifications to the font size of the flashcards, changes in the color of some flashcards, and the addition of more images to the flashcards. One of the professors said, "Add the pronunciation of the terms to the flashcards by writing their phonetics on the cards." Another professor said, "I think you should change the colors you have used for the body systems. If you could use red for cardiovascular and yellow for the nervous system, it was much better." Another one said, "If the color of the systems is used based on the real color of the systems, it would be more beneficial; for example, red for heart and blood and cardiovascular system." As for adding images to flashcards, one of the professors said, "Add images and pictures to the flashcards as they will help students' visual learning." Another professor said, "The appearance of the flashcards is the most important part of the flashcards; change the font size as some words cannot be read easily." The modifications which the professors had suggested in the interviews were considered and fine-tuned medical terminology flashcards were prepared for use in the medical terminology courses.

\section{Discussion}

This study was set out with the aim of creating medical terminology flashcards to be used in the medical terminology and specialized English courses in medical sciences universities in response to the educational challenges and the existing lack of teaching and learning materials. It also aimed to evaluate the flashcards from the perspective of professors to ensure their usability in the courses. The rationale behind developing the flashcards was the improvement of the quality of teaching medical terms by using teaching aids in the medical terminology course and the lack of ready-made medical terminology flashcards in the market. A reason for producing the flashcards was that medical flashcards might be available on the Internet, but they may not be comprehensive enough to cover a two-credit course on medical terminology. Additionally, the available flashcards on the Internet do not contain Persian equivalents of medical terms and other features helping students, who are at different levels of English language proficiency, learn the medical terms. 
Another reason for producing the flashcards, as was mentioned earlier, was the shortage of such medical terminology flashcards in the Iranian context. The flashcards were produced so that the students could have access to the educational materials and continue their medical terminology studies independently. An attempt was made to incorporate as many features as possible on the flashcards. Another reason which further intensified the motivation for the production of the flashcards was the need for a change in the teaching of medical terminology and specialized English courses. As the "accurate writing, coding, and analysis of medical data contained in health records depend on their knowledge of medical terminology" (Davies, 2007) and "medical students must learn specialist vocabulary since it is necessary for the development of all the skills which are required in their professional setting" (Donesch-Jezo, 2014), the students in medical fields should be supported for learning the medical terms. Moreover, flashcards in the form of teaching and learning aids or take-home packages are one of the learning materials and learning aids that could be used during the pandemics. Therefore, the development of flashcards to be used in university courses is justified as it contributes to the continuity of quality education.

The present study also investigated the medical sciences professors' evaluation of the created medical terminology flashcards. To use the flashcards extensively and officially in the university classes, we needed to learn about the faculty members' evaluation of the appearance, content, and potential learning effect of the flashcards. The experienced faculty members' evaluation was sought as a confirmation and certification of the usability of the flashcards so that they could be subsequently used in the university classes confidently. Like many other studies, the professors in the present study evaluated the flashcards positively. The professors' positive evaluation of the flashcards could have been for the care and precision in the development of the flashcards.

There is, however, a difference in the evaluation of flashcards in different studies. Nakata (2011) reports that flashcards should be evaluated in terms of flashcard creation, editing, and learning criteria. Likewise, Canova (2000) argues that in the evaluations of teaching aids, scales like contents, the formal characteristics, technicalities, and the learning process should be considered. The professors in the present study evaluated the flashcards in terms of the appearance and structure of the flashcards, the content of the information on the flashcards, and the potential effect of the flashcards on the students' learning. Other studies on flashcard production have evaluated the flashcards as a whole and have not considered different dimensions of the flashcards. Dashti et al. (2018), for example, used a 13-item checklist to discover students' evaluation of flashcards. Patil and Iyer (2016) also used no criteria on the appearance and structure of the flashcards to evaluate them. The items they used for evaluating the flashcards focused on the effect of the flashcards on learning. From the discussion on the evaluation of flashcards, it can be safely argued that the evaluation of the flashcards in the present study was comprehensive. Like any other study, the present study had some limitations. One of the limitations of the study was the limited number of professors having experience in teaching medical terminology.

\section{Conclusion}

Motivated by the existing scarcity of and need for medical terminology materials, this study attempted to contribute to the quality teaching of medical terms by creating medical terminology flashcards. The study also aimed to evaluate the flashcards from the professors' perspective to ensure that the flashcards would meet the criteria for inclusion in the medical terminology and specialized language courses at medical sciences universities. The flashcards were produced after analyzing the students' needs, designing the rough versions of the flashcards, and examining them. The results of the professors' evaluation of the flashcards showed that they were satisfied with the potential effects of the flashcards on the students' learning; they also believed that the flashcards could be used practically in university courses.

Despite their overall positive evaluation, the professors called for a few modifications to the color and font size of the flashcards and suggested the addition of further linguistic information to the flashcards. After making the modifications, a set of medical terminology flashcards were finalized for use in the university courses. Therefore, the present study could help fill in the gap in the educational materials needed for medical terminology courses. From the findings, it can be concluded that professors can play a positive role in improving the quality of teaching by creating educational materials. The study suggests that other types of flashcards in the form of mobile applications, digital flashcards, and take-home packages should be produced and used in university courses. Moreover, future studies can investigate the effects of different kinds of flashcards on students' academic achievement. 


\section{Acknowledgments}

This paper has been extracted from a scholarship of teaching and learning (SoTL) research project. The project was funded by the National Agency for Strategic Research in Medical Education in Tehran, Iran. Grant No. 972953. We would like to express our gratitude to all the officials and individuals who helped us complete the study.

\section{References}

Akhoundzadeh, K., Salehi, S., \& Yousefi, M. H. (2010). Nursing students' viewpoints towards routine instructional tools. Iranian Journal of Medical Education, 10(3), 269-276. http://ijme.mui.ac.ir/article-1-1414-en.html

Baleghizadeh, S., \& Ashoori, A. (2011). The impact of two instructional techniques on EFL learners' vocabulary knowledge: $\quad$ Flashcards $\quad$ versus $\quad$ wordlists. Mextesol Journal, 35(2), 1-9. http://mextesol.net/journal/public/files/d8449b5efc1a65123512b9a73b780140.pdf

Bryson, D. (2012). Using flashcards to support your learning. Journal of Visual Communication in Medicine, 35(1), 25-29. https://doi.org/10.3109/17453054.2012.655720

Cohen, B. J., \& DePetris, A. (2018). Medical terminology: an illustrated guide. Lippincott Williams \& Wilkins, Philadelphia.

Dashti, G., Golshan Iranpour, F., Salimi, M., Akbari, M., Mohammadi Chamnari, F., \& Ghasemi, N. (2018). Impact of educational flash cards on improved learning of skull radiotherapy techniques. Anatomical Sciences, 15(2), 73-76. http://anatomyjournal.ir/article-1-180-en.html

Davies, J. J. (2007). Essentials of medical terminology (3rd ed.). Delmar Learning.

Donesch-Jezo, E. (2014). Teaching of vocabulary to medical students in ESP courses. LangLit, 1(1), 72-87.

Dörnyei, Z. (2010). Questionnaires in second language research: Construction, administration, and processing (2nd ed.). London: Routledge.

Farrokhi, F., Zohrabi, M., \& Bolandnazar, A. (2021). The role of flashcard and wordlist strategies with concrete vs. abstract words on Iranian EFL learners' vocabulary development. Iranian Journal of English for Academic Purposes, 10(1), 88-107. http://journalscmu.sinaweb.net/article_128851.html

Hagood, M. C. (2012). Risks, rewards, and responsibilities of using new literacies in middle grades. Voices from the Middle, 19(4), 10-16. https://eric.ed.gov/?id=EJ976265

Hu, H. P., \& Deng, L. J. (2007). Vocabulary acquisition in multimedia environment. US-China Foreign Language, 5(8), 55-59. https://citeseerx.ist.psu.edu/viewdoc/download?doi=10.1.1.116.5159\&rep=rep1\&type=pdf

Huber, M. T., \& Hutchings, P. (2005). The advancement of learning: Building the teaching commons. San Francisco, CA: Jossey-Bass.

Khabiri, M., \& Khatibi, M. B. (2013). Mobile-assisted language learning: Practices among Iranian EFL learners. European Online Journal of Natural and Social Sciences, 2(2), 176-190. https://europeanscience.com/eojnss/article/view/152

Khorasani, R., \& Mirhosseini Chahardeh, S. M. (2018). The effect of pre-teaching new vocabulary items via audiovisuals on Iranian EFL learners' reading comprehension ability. International Journal of Research in English Education (IJREE), 3(1), 19-27. http://ijreeonline.com/article-1-88-en.html

Lisa, H. (2019). The effectiveness of flashcards on the motivation to increase English vocabulary among the fourth elementary school. Journal of Applied Linguistics and Literature, 4(1),43-53. https://ejournal.unib.ac.id/index.php/joall/article/view/6852

Mahdiloo, A., \& Izadpanah, S. (2017). The impact of humorous movie clips on better learning of English language vocabulary. International Journal of Research in English Education (IJREE), 2(2), 16-30. http://ijreeonline.com/article-1-45-en.pdf

McDonough, J., \& Shaw, C. (2003). Materials and methods in ELT. Oxford: Blackwell. 
Mohammadnejad, S., Nikdel, H., \& Oroujlou, N. (2012). Reactivating EFL learners' word knowledge by means of two techniques: Flashcards versus wordlists. International Journal of Linguistics, 4(4), 393-406. doi: https://doi.org/10.5296/ijl.v4i4.2913

Nakata, T. (2011). Computer-assisted second language vocabulary learning in a paired-associate paradigm: A critical investigation of flashcard software. Computer Assisted Language Learning, 24(1), 17-38. https://doi.org/10.1080/09588221.2010.520675

Nation, P. (2001). Learning vocabulary in another language. Cambridge: CUP.

Pakdaman, S., \& Pourhosein Gilakjani, A. (2019). The impact of collocation activities on Iranian intermediate EFL learners' knowledge of vocabulary. International Journal of Research in English Education (IJREE), 4(4), 70-82. doi: 10.29252/ijree.4.4.70

Patil, R., \& Iyer, P. (2016). Perceptions of undergraduate medical students on use of flashcards as a mode of learning anatomy. National Journal of Integrated Research in Medicine, 7(2), 110-112. http://nicpd.ac.in/ojs/index.php/njirm/article/view/1369

Rubdy, R. (2003). Selection of materials. In B. Tomlinson (ed.) Developing materials for language teaching (pp. 3757). London: Continuum.

Seidlein, A., Bettin, H., \& Franikowski, P. (2020). Gamified E-learning in medical terminology: the TERMInator tool. BMC Med Educ, 20, 284. https://doi.org/10.1186/s12909-020-02204-3

Shamsi, M., \& Rahimy, R. (2017). The impact of L2 semantic tasks (L2 collocation versus L2 definition) on Iranian intermediate EFL learners' vocabulary achievement. International Journal of Research in English Education (IJREE), 2(1), 58-67. http://ijreeonline.com/article-1-30-en.html

Sitompul. E. Y. (2013). Teaching vocabulary using flashcards and word list. Journal of English and Education, 1(1), 52-58. https://media.neliti.com/media/publications/192296-EN-none.pdf

Taghizadeh, M., \& Porkar, P. (2018). Tablet, flashcard and SMS and their effects on EFL learners' attitudes and vocabulary knowledge. International Journal of English Language \& Translation Studies, 6(1), 105-118. http://www.eltsjournal.org/archive/value6\%20issue1/12-6-1-18.pdf

Tomlinson, B. (1998). Materials development in language teaching. Cambridge: Cambridge University Press.

Tomlinson, B. (2003). Developing materials for language teaching. London: Continuum.

Yüksel, H., G., Mercanoğlu, H., G., \& Yılmaz, M. B. (2020). Digital flashcards vs. wordlists for learning technical vocabulary. Computer Assisted Language Learning. doi: 10.1080/09588221.2020.1854312 